\title{
Effect of the Composition of CAD/CAM Composite Blocks on Mechanical Properties
}

\author{
Rasha A. Alamoush, ${ }^{1,2}$ Nick Silikas $\mathbb{D}^{1},{ }^{1}$ Nesreen A. Salim, ${ }^{2}$ \\ Suhad Al-Nasrawi, ${ }^{1,3}$ and Julian D. Satterthwaite ${ }^{1}$ \\ ${ }^{1}$ School of Dentistry, The University of Manchester, Manchester, UK \\ ${ }^{2}$ Prosthodontic Department, University of Jordan, Amman, Jordan \\ ${ }^{3}$ Faculty of Dentistry, University of Kufa, Najaf, Iraq \\ Correspondence should be addressed to Nick Silikas; nick.silikas@manchester.ac.uk
}

Received 25 August 2018; Accepted 9 October 2018; Published 23 October 2018

Academic Editor: Elena Landi

Copyright (c) 2018 Rasha A. Alamoush et al. This is an open access article distributed under the Creative Commons Attribution License, which permits unrestricted use, distribution, and reproduction in any medium, provided the original work is properly cited.

\begin{abstract}
The aim of this study was to evaluate the effect of the composition of CAD/CAM blocks on their mechanical properties. Nine different CAD/CAM blocks, enamel and dentine, were tested. Sixteen samples of each material were separated for Vickers microhardness test ( $n=6,5$ readings per specimen), nanohardness test $(n=6,5$ readings per specimen), filler weight $(n=3)$, and SEM imaging $(n=1)$. Data were statistically analysed using one-way ANOVA. Vita Mark II ceramic showed significantly higher values of hardness (in both nano- and microscale) and elastic modulus $\left(6.83 \mathrm{GPa}, 502 \mathrm{~kg} / \mathrm{mm}^{2}\right.$, and $\left.47.7 \mathrm{GPa}\right)$, respectively, than other materials. CAD/CAM composite blocks showed comparable values of hardness and elastic modulus to those of dentine but lower than those of enamel and ceramics. SEM images highlighted different filler-matrix microstructure of CAD/CAM composite blocks. It was concluded that (1) hardness and elastic moduli are positively correlated with ceramic filler percentage and microstructure and (2) CAD/CAM composite materials have comparable hardness and elastic moduli to tooth structure.
\end{abstract}

\section{Introduction}

Alternative aesthetic restorations have been introduced, as the digital technologies of CAD/CAM systems have been developed. Ceramic and composite have been used as indirect restorations using CAD/CAM systems as promising restorations [1]. In addition, PEEK has been proposed for CAD/CAM prosthodontics applications [2].

Ceramic has favourable properties for use as an indirect restorative material; it is a very biocompatible and strong material [1-3]. However, it is very stiff, hard, and brittle; these properties affect its clinical performance, durability, and machinability. In terms of their hardness and stiffness, ceramics are considered highly abrasive. This affects the material performance in two aspects: first, clinically, ceramic might cause opposing enamel wear and roughness $[4,5]$. Second, it is difficult to machine; for instance, in CAD/CAM systems ceramic hardness causes milling tool damage over time; also it takes longer to mill compared with composite $[6,7]$. The other main disadvantage of ceramics is brittleness. Again, it affects the material in two main aspects: First, ceramic clinical durability is highly related to their brittleness; most ceramic restorations fail because of crack propagation due to the material brittleness [8]. Second, in terms of machinability, ceramic might chip or crack during processing. Hence it is difficult to manufacture even with CAD/CAM systems [9].

Over the years, indirect composite restorations have improved in relation to their mechanical properties in different ways: alteration of the composition (monomer resins, initiation systems); incorporation of high percentage filler particles; and polymerization modes (using high temperature and pressure for polymerization) $[10,11]$. These have improved both tensile and compressive strength, hardness, elastic modulus [12], and wear resistance [13, 14]. CAD/CAM technology allows for many of these alterations in manufacturing to result in improved indirect composite restorations.

CAD/CAM composite has the following main advantages compared to ceramic: it has less hardness and stiffness, so 
the opposing enamel exhibits less wear clinically. In addition, it is easily fabricated and repaired. It is also less brittle [15]. Consequently, less catastrophic failure is expected as well as less chipping and crack introduction during manufacturing [9]. In addition, they are more compatible with milling machine and exhibit better marginal quality $[9,10,16]$.

Different formulations have been introduced recently with different material classifications such as ceramic-like materials, polymer infiltrated ceramics, CAD/CAM resin based blocks, or nanoceramics [3,17]. CAD/CAM composites can be classified based on their microstructural geometry into two main types, resin with dispersed fillers and polymer infiltrated ceramic networks [18].

PEEK has favourable mechanical properties [19]. It has similar tensile properties to those of bone, enamel, and dentine [20]. Therefore, it has been proposed for use in fixed [21] and removable prostheses [22]. Further investigation of CAD/CAM composites in many aspects such as mechanical properties, bonding, and biocompatibility is highly needed. Most importantly, their mechanical properties such as flexural strength, flexural modulus, modulus of resilience, and hardness that can predict the material clinical success and performance are important to be evaluated [23-25].

In the view of limited research on CAD/CAM composite blocks and the need to evaluate their clinical success and performance, this study aimed to test the mechanical properties (hardness, elastic modulus, and microstructure) of different CAD/CAM blocks and compare them to ceramic, enamel, and dentine using two indentation techniques (nanoindentation and Vickers hardness). The null hypotheses were that (1) there is no difference in the tested mechanical properties between materials and (2) the mechanical properties of the tested materials will not be affected by the their composition.

\section{Materials and Methods}

2.1. Study Design. Nine different CAD/CAM blocks were tested ( $n=16$ each group). Enamel and dentine discs were prepared from extracted wisdom teeth ( $n=12$, each group). Samples of each material were allocated into two groups: Vickers microhardness test $(n=6)$ and nanohardness test $(n=6)$. In addition 4 samples (of each CAD/CAM block) were used for filler weight test $(n=3)$ and SEM imaging $(n=1)$. The microhardness was measured by means of a Vickers indenter tester (FM-700, Future Tech Corp., Japan). The test parameters were with load of $300 \mathrm{~g}$ and $20 \mathrm{~s}$ dwell time. Nanoindentation measurements (elastic modulus, hardness) were undertaken using a nanoindenter (M3 Nanovea, Nanovea Co., CA, USA) equipped with a Berkovich three-sided pyramidal diamond tip. The machine was set for the chosen parameters: load of $20 \mathrm{~g}$ and pause of $20 \mathrm{~s}$. Thirty indentations on 6 samples ( 5 for each) were made for each material for each test. SEM images at 1000x and 5000x magnifications were obtained to assess filler-matrix microstructure of hybrid ceramics. Data were statistically analysed using one-way ANOVA. block (Lava Ultimate, Shofu, Cerasmart, Brilliant Crios, Grandio Blocs); polymer infiltrated ceramic network (PICN) ceramic block (Enamic); pure PEEK (Ceramill PEEK); ceramic filled PEEK (Dentokeep); and feldspathic ceramic block (Vitablocs Mark II). Enamel and dentine discs were prepared from extracted wisdom teeth. A list of materials studied, with details of filler percentage and polymer, is given in Table 1.

Six specimens of each of the 11 materials were prepared (9 CAD/CAM blocks, enamel and dentin). Each CAD/CAM block was sectioned into rectangular bars of $2 \mathrm{~mm}$ thickness using a diamond blade (MK 303, MK diamond, CA, USA) mounted on a saw (Isomet 1000 Precision Cutter; Buehler Co, IL, USA) under constant water irrigation (ISO 6872:2008) [26]. Discs of $2 \mathrm{~mm}$ of enamel and dentine were prepared from extracted wisdom teeth from young adults (ethical approval was granted by NHS, Health Research Authority, London, Harrow Research Ethics Committee (15/LO/1545)) and disinfected with $20 \mathrm{ml}$ of $5 \%$ sodium hypochlorite for $10 \mathrm{~min}$ (301696S, BDH Chemicals Ltd., Poole, BH15, England) and then wrapped in cotton gauze saturated with physiologic saline (59300C, Dulbecco's Phosphate Buffered Saline, Sigma-Aldrich Inc., St. Louis, USA) and kept at $4^{\circ} \mathrm{C}$ to be prepared and tested within a week.

All specimens were wet ground and polished with a lapping machine (MetaServ 250, Buehler Co, IL, USA) with a series of silicon carbide papers $(\mathrm{SiC})$ and paper disks P320, P500, P1200, P2400, and P4000-grit (Buehler Co, Illinois, USA) under water cooling and then polished with 0.25 um diamond suspension (Meta Di Supreme, Buehler Co, IL, USA) and cleaned in an ultrasonic bath (Ultrasonic Cleaning System, L\&R Co, NJ, USA) with distilled water for $5 \mathrm{~min}$. The specimens were stored dry for $24 \mathrm{hr}$ at room temperature.

2.3. Nanoindentation. Elastic modulus and hardness measurements (nanoindentation measurements) were obtained using a nanoindenter (M3 Nanovea, Nanovea, Co., CA, USA) equipped with a Berkovich three-sided pyramidal diamond tip which was used with indenter cone angle 130.54 and elastic modulus of $1140 \mathrm{GPa}$.

Calibration indents were made on a fused silica sample with an elastic modulus of $71.3 \mathrm{GPa}$ and hardness of $8.9 \mathrm{GPa}$. The machine was set for the chosen parameters, load of $20 \mathrm{~g}$, and pause of $20 \mathrm{~s}$. Poisson's ratio for all tested materials was assumed to be 0.3 . Thirty indentations were undertaken ( 5 for each sample) for each material at room temperature. The maximum load applied by the nanoindenter to examine the specimens was $20 \mathrm{~g}$. The machine calculated the elastic modulus $(\mathrm{E})$ and nanohardness $(\mathrm{H})$ by using the generated force-displacement curves from nanoindentation testing, based on the Oliver-Pharr method [27], using the following equations, respectively:

$$
E=\frac{1}{2} \times \frac{\sqrt{ } \pi}{\sqrt{ } \mathbf{A}} \times \frac{\mathrm{dh}}{\mathrm{dP}}
$$


TABLE 1: Materials tested and manufacturer's information.

\begin{tabular}{|c|c|c|c|c|}
\hline \multirow{2}{*}{$\begin{array}{l}\text { Material } \\
\text { type }\end{array}$} & \multirow{2}{*}{$\begin{array}{l}\text { Materials } \\
\text { (Code) }\end{array}$} & \multicolumn{2}{|c|}{ Composition by weight } & \multirow[t]{2}{*}{ Manufacturer } \\
\hline & & Filler & polymer & \\
\hline \multirow{5}{*}{$\begin{array}{l}\text { Resin composite CAD } \\
\text { CAM blocks }\end{array}$} & Lava $^{\mathrm{TM}}$ - Ultimate (LU) & $\begin{array}{l}80 \% \text { silica and } \\
\text { zirconia nano } \\
\text { particles }\end{array}$ & $\begin{array}{l}\text { 20\% ( Bis-GMA, } \\
\text { UDMA, Bis-EMA, } \\
\text { TEGDMA) }\end{array}$ & $3 \mathrm{M}^{\mathrm{TM}} \mathrm{ESPE}^{\mathrm{TM}}$ USA \\
\hline & Shofu (SH) & $\begin{array}{l}\text { 61\% Silica-based glass } \\
\text { and silica }\end{array}$ & UDMA+TEGDMA & Shofu \\
\hline & Cerasmart (CS) & $\begin{array}{l}\text { 71\% Silica and barium } \\
\text { glass nanoparticles }\end{array}$ & $\begin{array}{l}\text { Bis-MEPP, UDMA, } \\
\text { DMA }\end{array}$ & $\begin{array}{c}\text { GC dental products, } \\
\text { Europe }\end{array}$ \\
\hline & $\begin{array}{l}\text { BRILLIANT Crios } \\
\text { (BC) }\end{array}$ & $\begin{array}{l}70 \% \text { of glass and } \\
\text { amorphous silica }\end{array}$ & $\begin{array}{c}\text { Cross-linked } \\
\text { methacrylates } \\
\text { (Bis-GMA, Bis-EMA, } \\
\text { TEGDMA) }\end{array}$ & $\begin{array}{l}\text { COLTENE, } \\
\text { Switzerland }\end{array}$ \\
\hline & Grandio Blocs (GR) & $\begin{array}{l}86 \% \text { Nanohybrid } \\
\text { fillers }\end{array}$ & $14 \%$ UDMA+ DMA & VOCO GmbH \\
\hline $\begin{array}{l}\text { Polymer infiltrated } \\
\text { ceramic network (PICN) } \\
\text { ceramic }\end{array}$ & $\begin{array}{l}\text { Vita Enamic } \\
\qquad(\mathrm{EN})\end{array}$ & $86 \%$ ceramic & $\begin{array}{c}14 \% \\
\text { UDMA+TEGDMA }\end{array}$ & $\begin{array}{l}\text { Vita Zahnfabrik, } \\
\text { Germany }\end{array}$ \\
\hline Pure PEEK & Ceramill PEEK (PE) & 0 & 100\% PEEK & Juvora, UK \\
\hline Ceramic filled PEEK & Dentokeep (DK) & $20 \% \mathrm{TiO}_{2}$ & $80 \%$ PEEK & Nt-trading Germany \\
\hline $\begin{array}{l}\text { Feldspathic ceramic } \\
\text { block }\end{array}$ & $\begin{array}{l}\text { Vitablocs Mark II } \\
\text { (VM) }\end{array}$ & $\begin{array}{l}\text { Fine-particle feldspar } \\
\text { ceramic }\end{array}$ & 0 & $\begin{array}{l}\text { Vita Zahnfabrik, } \\
\text { Germany }\end{array}$ \\
\hline
\end{tabular}

where $\mathrm{A}$ is the projected contact area; $\mathrm{dh}$ is the change in depth; $\mathrm{dP}$ is the difference in load.

$$
\mathrm{H}=\frac{\operatorname{Pmax}}{\mathrm{A}}
$$

where $\mathrm{A}$ is the projected contact area; Pmax is the maximum load.

2.4. Vickers Microhardness. Surface microhardness was measured by means of a Vickers indenter tester (FM-700, Future Tech Corp., Japan) under a $300 \mathrm{~g}$ loading and $20 \mathrm{~s}$ dwell time. For each indentation, both diagonals (D1, D2) were measured using the microscope. Five indents were undertaken for each sample in a straight line. The distance between the indentations was calculated by multiplying the average indentation diagonal length by four $(4 * \mathrm{D})$ to ensure sufficient distance between the indentations. Five indentations were undertaken on each specimen and the hardness values were averaged. Thirty determinations on 6 samples were made for each material. The machine then automatically calculated the corresponding hardness value and presented it as VHN. Vickers microhardness can also be calculated using the following equation [28]:

$$
\mathrm{VHN}=1.854 \frac{\mathrm{P}}{\mathrm{D}^{2}}
$$

where $\mathrm{P}$ is the applied load in $\mathrm{kg}$ and $\mathrm{D}$ is the indentation diagonal length in $\mathrm{mm}$.

2.5. Filler Content. The mass percentage of inorganic filler content of the CAD/CAM blocks was measured by elimination of the organic part of the CAD/CAM blocks by heating at a constant temperature (ash technique) in accordance with ISO 1172:1996 [29]. Thermogravimetric analysis (TGA) is an alternative method to measure the filler content and is possibly more accurate. Three samples of each material $(n=3)$ were kept in an electric furnace (Programat EP 5000, Ivoclar Vivadent, Liechtenstein, Austria) set at $625^{\circ} \mathrm{C}$ for $30 \mathrm{~min}$ and then cooled in a desiccator. The samples were then weighed to an accuracy of $0.01 \mathrm{mg}$ using a calibrated electronic analytical balance (Ohaus Analytical Plus, Ohaus Corporation, USA). The percentage of inorganic fillers by weight was then determined using the following equation:

$$
\text { Filler weight } \left.\%=\left[\left(100-\left(\frac{(\mathrm{m} 1-\mathrm{m} 2)}{\mathrm{m} 1}\right)\right) \times 100 \%\right)\right]
$$

with $\mathrm{m} 1$ being the mass before heating and $\mathrm{m} 2$ the mass after heating and cooling.

2.6. Microstructure. The surfaces of the specimens were wet polished using $\mathrm{SiC}$ paper P600 up to P4000 and diamond solutions of $9,3,1$, and $0.25 \mu \mathrm{m}$ and subsequently ultrasonically cleaned with acetone for $5 \mathrm{~min}$. The specimens were dried, mounted on aluminium stubs, and sputter-coated with carbon. The surface of each specimen was examined using a scanning electron microscope (SEM; FEI Quanta200, OH, USA) and SEM images at 1000x and 5000x magnifications at $10 \mathrm{kV}$ were obtained.

2.7. Statistical Analysis. All results were tested using Levene's test for homogeneity of variance $(\mathrm{P}<0.05)$, following the assumption of equal variances. Equal variances were confirmed $(\mathrm{P}>0.05)$; hence the Bonferroni post hoc test was used to determine the differences in the mechanical properties 
TABLE 2: Mean (SD) Vickers microhardness, nanohardness, elastic modulus, and the measured and manufacturers' filler percentages by weight (wt\%) for all tested materials. Values with the same superscript letters per column represent nonsignificant statistical difference for each individual property $(\alpha=0.05)$.

\begin{tabular}{|c|c|c|c|c|c|c|}
\hline $\begin{array}{l}\text { Material } \\
\text { type }\end{array}$ & $\begin{array}{l}\text { Material } \\
\text { (code) }\end{array}$ & $\begin{array}{l}\text { Microhardness } \\
\left(\mathrm{Kg} / \mathrm{mm}^{2}\right)\end{array}$ & $\begin{array}{c}\text { Nanohardness } \\
(G P a)\end{array}$ & $\begin{array}{c}\text { Elastic Modulus } \\
(\mathrm{GPa})\end{array}$ & $\begin{array}{c}\text { Manufacturers' } \\
\text { Filler } \\
(w t \%) \\
\end{array}$ & $\begin{array}{c}\text { measured filler } \\
(w t \%)\end{array}$ \\
\hline \multirow{5}{*}{$\begin{array}{l}\text { Resin composite } \\
\text { CAD/CAM blocks }\end{array}$} & $\begin{array}{c}\text { Lava }^{\mathrm{TM}}- \\
\text { Ultimate (LU) }\end{array}$ & $112.6(0.44)^{\mathrm{c}}$ & $1.25(0.05)^{c}$ & $12.14(0.76)^{\mathrm{c}}$ & 80 & $74.8(0.1)$ \\
\hline & Shofu (SH) & $73.12(1.04)^{\mathrm{d}, \mathrm{f}}$ & $0.775(031)^{\mathrm{d}}$ & $8.79(0.35)^{c, \mathrm{~d}, \mathrm{e}}$ & 61 & $63(0.02)$ \\
\hline & Cerasmart (CS) & $80.06(0.76)^{\mathrm{d}}$ & $0.81(0.006)^{\mathrm{d}}$ & $10.36(0.17)^{c, d, e}$ & 70 & $66.1(0.2)$ \\
\hline & $\begin{array}{c}\text { BRILLIANT } \\
\text { Crios (BC) }\end{array}$ & $82.61(0.49)^{\mathrm{d}}$ & $0.85(0.008)^{\mathrm{d}}$ & $10.98(0.6)^{\mathrm{c}, \mathrm{e}}$ & 71 & $70.1(0.05)$ \\
\hline & $\begin{array}{c}\text { Grandio Blocs } \\
(\mathrm{GR})\end{array}$ & $121.8(2.1)^{\mathrm{c}}$ & $1.3(0.08)^{c}$ & $14.8(0.4)^{\mathrm{c}}$ & 86 & $84.6(0.01)$ \\
\hline $\begin{array}{l}\text { Polymer infiltrated } \\
\text { ceramic network } \\
(\mathrm{PICN}) \text { ceramic }\end{array}$ & $\begin{array}{l}\text { Vita Enamic } \\
(\mathrm{EN})\end{array}$ & $203.1(0.43)^{b}$ & $3.1(0.17)^{\mathrm{b}}$ & $34.56(1.4)^{b}$ & 86 & $85.1(0.1)$ \\
\hline Pure PEEK & $\begin{array}{c}\text { Ceramill PEEK } \\
(\mathrm{PE})\end{array}$ & $25.7(0.05)^{\mathrm{g}}$ & $0.317(0.008)^{\mathrm{e}}$ & $2.53(0.15)^{\mathrm{d}}$ & 0 & $.00(0)$ \\
\hline Ceramic filled PEEK & Dentokeep (DK) & $27.74(0.19)^{g}$ & $0.34(0.03)^{\mathrm{e}}$ & $3.43(0.29)^{\mathrm{d}, \mathrm{e}}$ & 20 & $27.5(0.06)$ \\
\hline $\begin{array}{l}\text { Feldspathic ceramic } \\
\text { block }\end{array}$ & $\begin{array}{c}\text { Vitablocs Mark } \\
\text { II (VM) }\end{array}$ & $502.4(2.28)^{\mathrm{a}}$ & $6.83(0.379)^{\mathrm{a}}$ & $47.7(3.47)^{\mathrm{a}}$ & 100 & $100(0)$ \\
\hline Enamel & EM & $313.3(22.7)^{\mathrm{h}}$ & $4.03(0.35)^{\mathrm{f}}$ & $59.7(13)^{\mathrm{f}}$ & - & - \\
\hline Dentine & $\mathrm{DN}$ & $62.3(3.3)^{f}$ & $0.76(0.13)^{\mathrm{d}}$ & $16.5(2.3)^{\mathrm{c}}$ & - & - \\
\hline
\end{tabular}

(hardness, elastic modulus, and microstructure). For the filler weight percentage measurement, Bland and Altman test was used to compare the measured values with the manufacturers' values where a minimal variation was detected with high level of reproducibility.

\section{Results}

Mean microhardness, nanohardness, and elastic modulus for all tested materials are shown in Table 2 and Figure 1. A statistically significant difference in the means of microhardness, nanohardness, and elastic modulus between the tested materials was revealed.

The values of nanohardness ranged from 0.31 (SD.008) GPa for pure PEEK to 3.1 (SD 0.17) GPa for Vita Mark II ceramic. The values of microhardness ranged from 25.7 (SD $0.05) \mathrm{Kg} / \mathrm{mm}^{2}$ for pure PEEK to 502.4 (SD 2.28) $\mathrm{Kg} / \mathrm{mm}^{2}$ for Vita Mark II ceramic. The values of elastic modulus ranged from 2.53 (SD 0.15) GPa for pure PEEK to 59.7 (SD 13) GPa for enamel.

The measured and manufacturers' filler percentages by weight are presented in Table 2. Measured values of filler content ranged from $100 \%$ (SD 0.0) weight for Vitablocs Mark II to 0.00 for pure PEEK. The measured filler percentage by weight was compared to the manufacturers' filler percentage. A Bland and Altman test shows minimal variation between results and high reproducibility. Elastic modulus, microhardness, and nanohardness were correlated with filler weight percentage and the results showed a positive correlation with linear regression: for filler weight percentage and microhardness $(\mathrm{VHN}), \mathrm{R}^{2}=0.43, \mathrm{P}=0.05$; for nanohardness
(GPa), $\mathrm{R}^{2}=0.38, \mathrm{P}=0.07$; for elastic modulus $(\mathrm{GPa}), \mathrm{R}^{2}=0.51$, $\mathrm{P}=0.03$ (Figure 2). In addition, the nanohardness and elastic modulus values were highly correlated where $\mathrm{R}^{2}=0.93$.

SEM images showed different microstructures of the tested CAD/CAM composite blocks (Figure 3). SH contained two varieties of spherical particles, CS contained relatively large and small and uniformly distributed particles, BC contained small and uniformly distributed particles, GR contained two varieties of particle, large and small irregularly shaped particles, LU contained a wide range of particle sizes, and EN exhibited a dense ceramic network structure with resin matrix. It can be noticed that CAD/CAM composite blocks had versatile microstructural constituents as well as variable filler weight percentages.

\section{Discussion}

The results of the present study show that the tested materials were significantly different in their mechanical properties (microhardness, nanohardness, and elastic modulus). CAD/CAM composite was significantly different from ceramics, enamel and dentine. Consequently, both null hypotheses were rejected.

It was noticed that CAD/CAM composite blocks had different microstructure as well as variable filler weight percentages and hence differences in the tested mechanical properties. However, it seems that the filler percentages have a more considerable role in these properties than do the microstructural constituents. In fact, PICN (EN) might be an exception as it exhibited higher values of hardness and elastic modulus compared to other CAD/CAM composite blocks, 


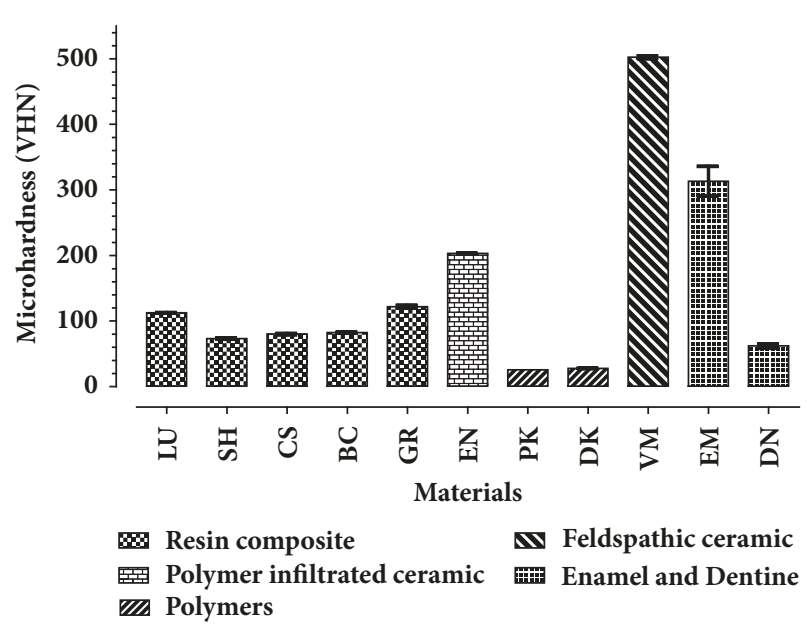

(a)

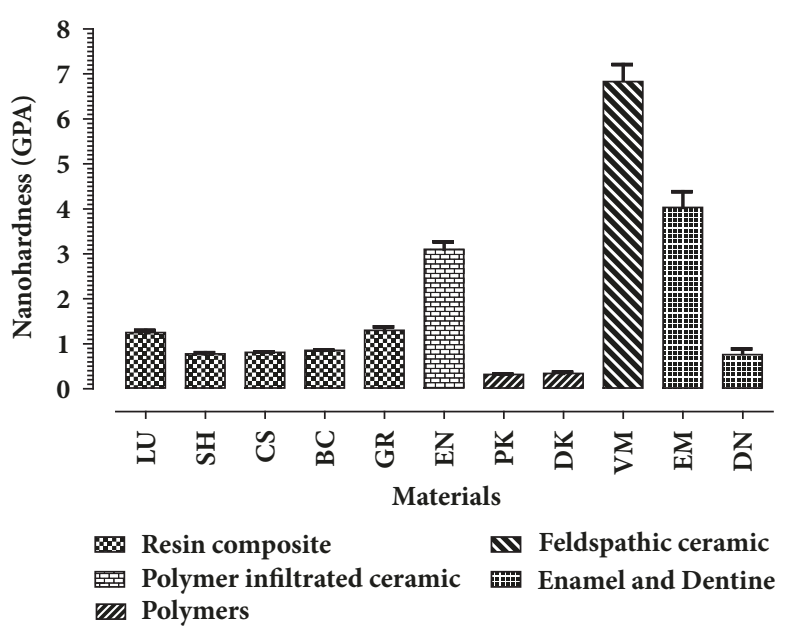

(b)

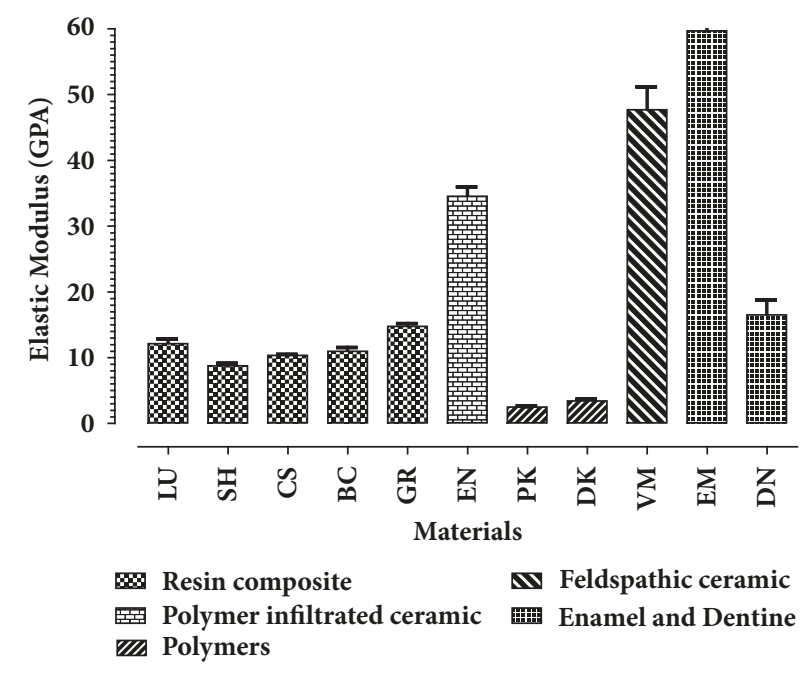

(c)

FIGURE 1: A bar chart showing the mean (a) Vickers surface microhardness (standard deviation); (b) nanohardness; (c) elastic modulus of eleven tested materials; resin composite CAD/CAM blocks (Lava Ultimate, Shofu, Cerasmart, Brilliant Crios, Grandio Blocs); polymer infiltrated ceramic network (PICN) ceramic block (Enamic); pure PEEK (Ceramill PEEK); ceramic filled PEEK (Dentokeep); and feldspathic ceramic block (Vitablocs Mark II); enamel and dentine.

which could be attributed to the manufacturing technique of polymer and ceramics networking.

Of the tested materials, Vita Mark II ceramic had the highest value of hardness (in both nano- and microscale) and elastic modulus, and it was significantly higher than the values of enamel and dentine rendering VM as very hard and stiff material. This might be considered a disadvantage in terms of machinability and durability $[9,25]$. Enamic showed higher hardness and elastic modulus values compared to other resin composite CAD/CAM blocks, which might be attributed to the robust microstructural geometry of PICN as compared to other resin composite CAD/CAM blocks which are basically a resin with dispersed ceramic fillers. The PICN VHN, nanohardness, and elastic modulus were in between the enamel and dentine values but closer to enamel values. The tested resin composite CAD/CAM blocks were closer in their characteristics to dentine rather than enamel.
The values of the elastic moduli of PICN (Enamic) $34.56 \mathrm{GPa}$ and resin composite CAD/CAM blocks are close to the values of enamel and dentine when compared to CAD/CAM ceramic which is very hard and stiff. This means they are closer to the tooth structure stiffness. Nonfilled and low filled ones (PEEK and Dentokeep) had lower hardness and elastic modulus values. These results were comparable with similar studies [10, 30-32].

The aim of any dental restorative material is to have similar characteristics to that of the toot structure [25, 33]. Hence, resin ceramic combination in a network structure exhibits the positive characteristics of ceramics and resin [24]. This material has low rigidity, hardness, and stiffness but high flexibility and fracture toughness [34, 35]. Resin with dispersed ceramic fillers has good fracture and wear resistance and high compressive strength [36]. 


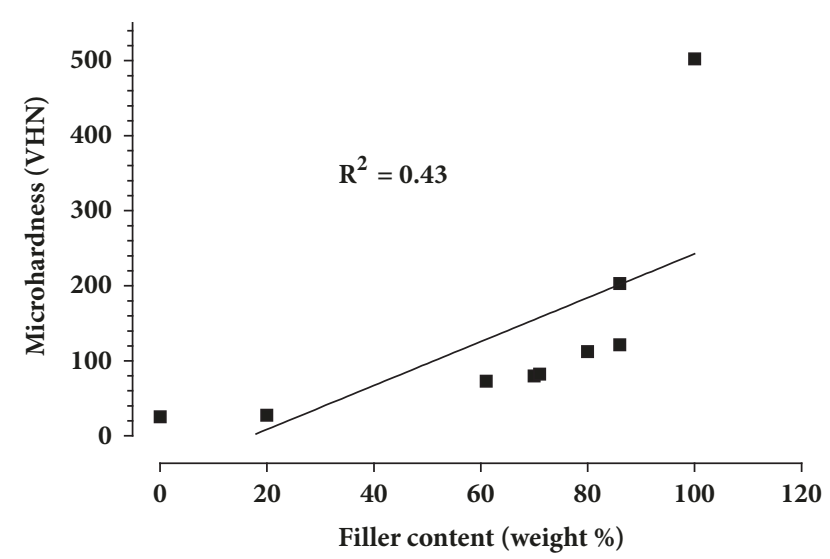

(a)

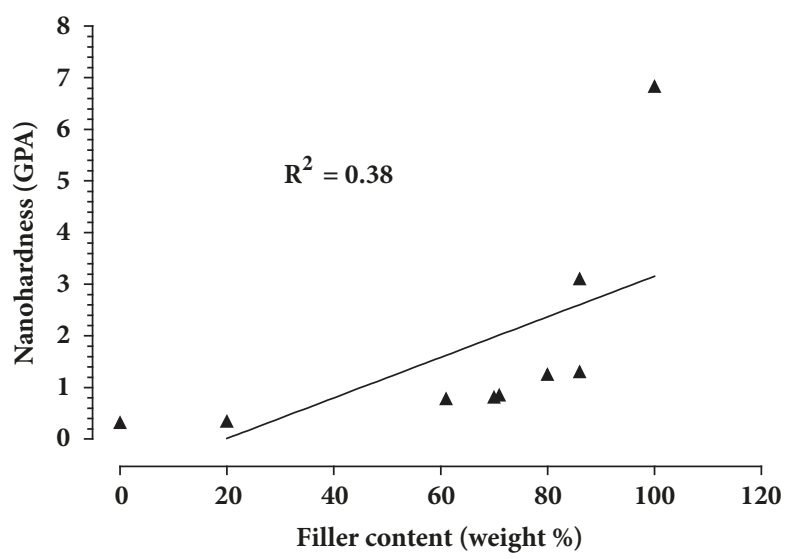

(b)

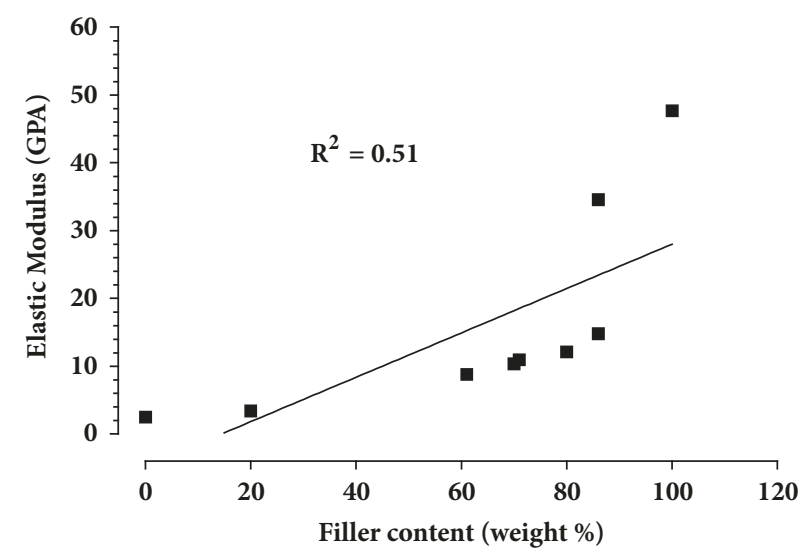

(c)

FIGURE 2: A scatter plot showing a positive correlation and linear regression between filler weight percentage and (a) microhardness (VHN), $\mathrm{R}^{2}=0.43, P=0.05$, (b) nanohardness (GPA), $\mathrm{R}^{2}=0.38, P=0.07$, and (c) elastic modulus (GPA), $\mathrm{R}^{2}=0.51, P=0.03$.
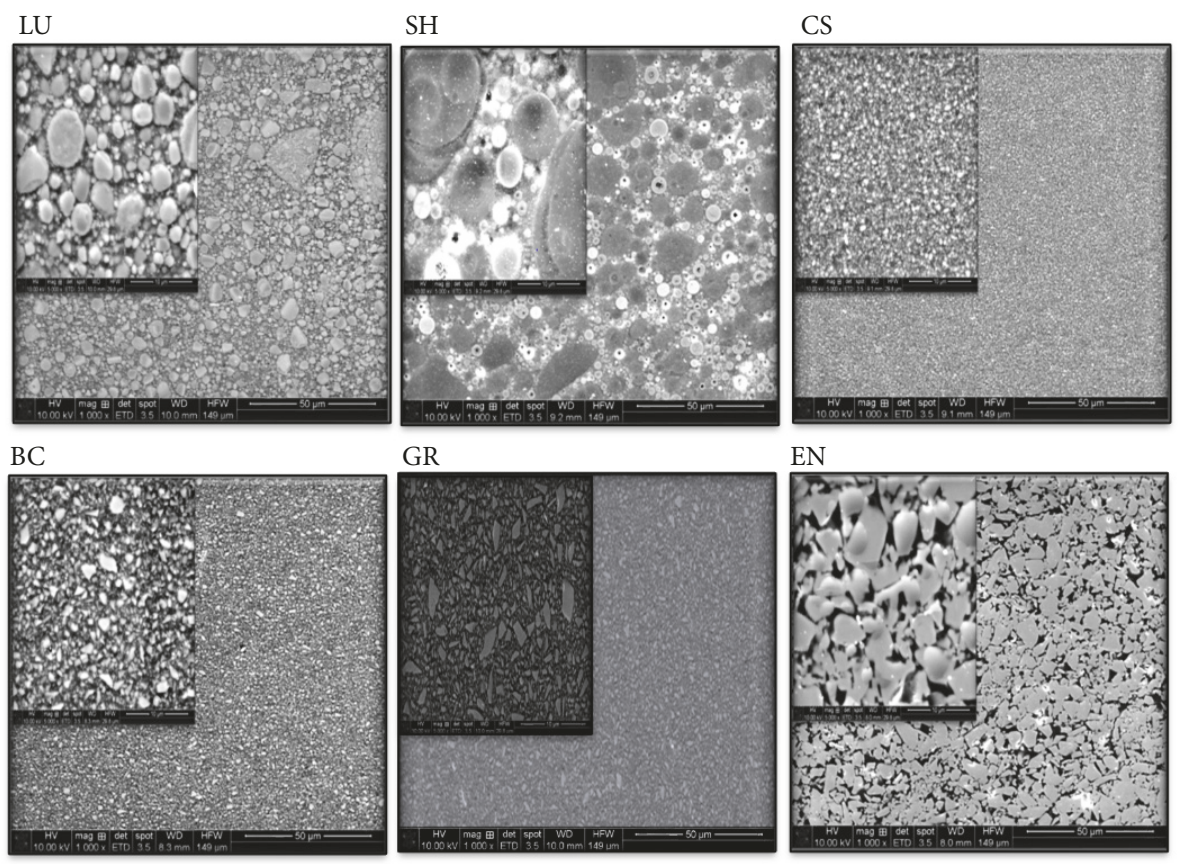

FIGURE 3: SEM images of CAD/CAM blocks of six tested materials at 5000x and 1000x magnifications at $10 \mathrm{Kv}$, detector; ETD, spot size 3.5, $\mathrm{WD} ; 10 \mathrm{~mm}$. 
PEEK showed favourable mechanical properties [19]. It has similar tensile properties to those of bone, enamel, and dentine [20]. Therefore, it has been proposed for use in fixed [21] and removable prostheses [22]. Although PEEK is increasingly used in fixed prosthodontics, the values of hardness and elastic modulus in this study were considerably low. However, for low percentage ceramic filled PEEK, the values were higher than pure PEEK; this is obviously attributed to the ceramic fillers. Low filled PEEK and PEEK have comparable hardness and stiffness values with PMMA. Hence, they might be a good choice for long-term restorations [32].

Nanoindentation is a well-documented method to measure the mechanical properties of both dental materials and teeth [37]. This test was used in this study to measure the elastic modulus as well as the hardness values of the tested materials at nanoscale. Using the microhardness test usually creates a relatively large indentation size of about $100 \mu \mathrm{m}$, while nanoindentation allows applying load as low as $30 \mathrm{mN}$ and indentation size less than $5 \mu \mathrm{m}$ [38].

Nanoindentation might be a more precise method to investigate materials with microstructural constituents, such as microfilled or nanofilled composites [39]. However, it has limitations, mainly that the test is very sensitive to thermal changes and mechanical vibration and acoustic noise [40]. Also the indenter tip size in relation to the filler particle size [41] and the maximum load used is relevant; i.e., if the indenter tip size or load were too small it would not provide sufficient information about the bulk material properties [39]. However, the appropriate indenter size along with appropriate load will provide sufficient information about the material properties. Also, there is no microscope linked to the Nanovea machine, so the location of the tested point can only be determined by naked eyes.

Vickers microhardness test is a versatile method that can be used to measure hardness for a wide range of materials and easy to employ. The main advantage is that the indentation geometry does not change due to different loads or different tested materials. However, there is an operator subjective variation as the indentation surface area is determined according to the average length of both diagonals (d) which can be determined microscopically by naked eyes [42].

Although both tests give hardness values, their values cannot be directly or simply compared due to the different testing mechanisms such as indenter type, test settings, and loading force. In nanoindentation the hardness depends on the applied load and indentation depth which is being measured as a function of the applied load (P) and the size of the contact area of indentation which depends on the geometry of the indenter [40]. However, in Vickers microhardness test, the hardness relies on the surface area of a square-shaped indentation. The indentation surface area is determined according to the average length of both diagonals (d) of the square-shaped indentation [28].

\section{Conclusions}

Within the limitations of this study, the following conclusions can be drawn: (i) The hardness and elastic moduli are positively correlated to ceramic filler percentage and microstructure.

(ii) CAD/CAM composite materials have comparable hardness and elastic moduli to tooth structure.

(iii) CAD/CAM composites combine ceramic good strength with composite lower hardness. But further in vivo work is warranted to determine its clinical relevance and serviceability.

\section{Data Availability}

The data used to support the findings of this study are included within the article.

\section{Conflicts of Interest}

The authors declare that they have no conflicts of interest.

\section{References}

[1] K. T. L. Barizon, C. Bergeron, M. A. Vargas et al., "Ceramic materials for porcelain veneers: Part II. Effect of material, shade, and thickness on translucency," Journal of Prosthetic Dentistry, vol. 112, no. 4, pp. 864-870, 2014.

[2] R. L. W. Messer, P. E. Lockwood, J. C. Wataha, J. B. Lewis, S. Norris, and S. Bouillaguet, "In vitro cytotoxicity of traditional versus contemporary dental ceramics," Journal of Prosthetic Dentistry, vol. 90, no. 5, pp. 452-458, 2003.

[3] I. Denry and J. R. Kelly, "Emerging ceramic-based materials for dentistry," Journal of Dental Research, vol. 93, no. 12, pp. 12351242, 2014.

[4] A. Lee, M. Swain, L. He, and K. Lyons, "Wear behavior of human enamel against lithium disilicate glass ceramic and type III gold," Journal of Prosthetic Dentistry, vol. 112, no. 6, pp. 13991405, 2014.

[5] D. J. Fasbinder, J. B. Dennison, D. Heys, and G. Neiva, "A clinical evaluation of chairside lithium disilicate CAD/CAM crowns: a two-year report," The Journal of the American Dental Association, vol. 141, supplement 2, pp. 10s-14s, 2010.

[6] N. Lebon, L. Tapie, E. Vennat, and B. Mawussi, "Influence of $\mathrm{CAD} / \mathrm{CAM}$ tool and material on tool wear and roughness of dental prostheses after milling," Journal of Prosthetic Dentistry, vol. 114, no. 2, pp. 236-247, 2015.

[7] R. Giordano, "Materials for chairside CAD/CAM-produced restorations," The Journal of the American Dental Association, vol. 137, pp. 14S-21S, 2006.

[8] J. LAMON and A. G. EVANS, "Statistical Analysis of Bending Strengths for Brittle Solids: A Multiaxial Fracture Problem," Journal of the American Ceramic Society, vol. 66, no. 3, pp. 177$182,1983$.

[9] E. A. Tsitrou, S. E. Northeast, and R. van Noort, "Brittleness index of machinable dental materials and its relation to the marginal chipping factor," Journal of Dentistry, vol. 35, no. 12, pp. 897-902, 2007.

[10] A. Awada and D. Nathanson, "Mechanical properties of resinceramic CAD/CAM restorative materials," Journal of Prosthetic Dentistry, vol. 114, no. 4, pp. 587-593, 2015.

[11] J. Nguyen, V. Migonney, N. D. Ruse, and M. Sadoun, "Resin composite blocks via high-pressure high-temperature polymerization," Dental Materials, vol. 28, no. 5, pp. 529-534, 2012. 
[12] S. Lin-Gibson, L. Sung, A. M. Forster, H. Hu, Y. Cheng, and N. J. Lin, "Effects of filler type and content on mechanical properties of photopolymerizable composites measured across two-dimensional combinatorial arrays," Acta Biomaterialia, vol. 5, no. 6, pp. 2084-2094, 2009.

[13] A. R. Cetin and N. Unlu, "Clinical wear rate of direct and indirect posterior composite resin restorations," International Journal of Periodontics and Restorative Dentistry, vol. 32, no. 3, pp. e87-e94, 2012.

[14] J.-F. Nguyen, V. Migonney, N. D. Ruse, and M. Sadoun, "Properties of experimental urethane dimethacrylate-based dental resin composite blocks obtained via thermo-polymerization under high pressure," Dental Materials, vol. 29, no. 5, pp. 535-541, 2013.

[15] N. D. Ruse and M. J. Sadoun, "Resin-composite blocks for dental CAD/CAM applications," Journal of Dental Research, vol. 93, no. 12, pp. 1232-1234, 2014.

[16] A. Coldea, J. Fischer, M. V. Swain, and N. Thiel, "Damage tolerance of indirect restorative materials (including PICN) after simulated bur adjustments," Dental Materials, vol. 31, no. 6, pp. 684-694, 2015.

[17] S. Gracis, V. P. Thompson, J. L. Ferencz, N. R. F. A. Silva, and E. A. Bonfante, "A new classification system for all-ceramic and ceramic-like restorative materials," International Journal of Prosthodontics, vol. 28, no. 3, pp. 227-235, 2015.

[18] A. K. Mainjot, N. M. Dupont, J. C. Oudkerk, T. Y. Dewael, and M. J. Sadoun, "From artisanal to CAD-CAM blocks: state of the art of indirect composites," Journal of Dental Research, vol. 95, no. 5, pp. 487-495, 2016.

[19] F. W. Zok and A. Miserez, "Property maps for abrasion resistance of materials," Acta Materialia, vol. 55, no. 18, pp. 63656371, 2007.

[20] R. B. Martin and J. Ishida, "The relative effects of collagen fiber orientation, porosity, density, and mineralization on bone strength," Journal of Biomechanics, vol. 22, no. 5, pp. 419-426, 1989.

[21] P. R. Schmidlin, B. Stawarczyk, M. Wieland, T. Attin, C. H. F. Hämmerle, and J. Fischer, "Effect of different surface pretreatments and luting materials on shear bond strength to PEEK," Dental Materials, vol. 26, no. 6, pp. 553-559, 2010.

[22] S. Costa-Palau, J. Torrents-Nicolas, M. Brufau-De Barberà, and J. Cabratosa-Termes, "Use of polyetheretherketone in the fabrication of a maxillary obturator prosthesis: A clinical report," Journal of Prosthetic Dentistry, vol. 112, no. 3, pp. 680-682, 2014.

[23] D. G. Charlton, H. W. Roberts, and A. Tiba, "Measurement of select physical and mechanical properties of 3 machinable ceramic materials," Quintessence International, vol. 39, no. 7, pp. 573-579, 2008.

[24] A. Della Bona, P. H. Corazza, and Y. Zhang, "Characterization of a polymer-infiltrated ceramic-network material," Dental Materials, vol. 30, no. 5, pp. 564-569, 2014.

[25] Y. Zhang and J. R. Kelly, "Dental Ceramics for Restoration and Metal Veneering," Dental Clinics of North America, vol. 61, no. 4, pp. 797-819, 2017.

[26] ISO. 6872:2008, Dentistry - Ceramic Materials, International Organization for Standardization, Geneva, Switzerland, 2008.

[27] W. C. Oliver and G. M. Pharr, "Measurement of hardness and elastic modulus by instrumented indentation: advances in understanding and refinements to methodology," Journal of Materials Research, vol. 19, no. 1, pp. 3-20, 2004.

[28] ISO/CD6507-1, Metallic Materials_Vickers Hardnesstest_Part 1: Test Method, 2006.
[29] "ISO. 1172: 1996. Textile-glass-reinforced plastics. Prepregs, moulding compounds and laminates. Determination of the textile glass and mineral-filler content. Calcination methods. Geneva: International Organization for Standardization," 1996.

[30] A. Coldea, M. V. Swain, and N. Thiel, "In-vitro strength degradation of dental ceramics and novel PICN material by sharp indentation," Journal of the Mechanical Behavior of Biomedical Materials, vol. 26, pp. 34-42, 2013.

[31] I. Thornton and N. D. Ruse, "Characterization of nanoceramic resin composite and lithium disilicate blocks," Journal of Dental Research, p. 93, 2014.

[32] A. Liebermann, T. Wimmer, P. R. Schmidlin et al., "Physicomechanical characterization of polyetheretherketone and current esthetic dental CAD/CAM polymers after aging in different storage media," Journal of Prosthetic Dentistry, vol. 115, no. 3, pp. 321-328.e2, 2016.

[33] M. Petrini, M. Ferrante, and B. Su, "Fabrication and characterization of biomimetic ceramic/polymer composite materials for dental restoration," Dental Materials, vol. 29, no. 4, pp. 375-381, 2013.

[34] S. E. Elsaka, "Influence of surface treatments on bond strength of metal and ceramic brackets to a novel CAD/CAM hybrid ceramic material," Odontology, vol. 104, no. 1, pp. 68-76, 2016.

[35] M. V. Swain, A. Coldea, A. Bilkhair, and P. C. Guess, "Interpenetrating network ceramic-resin composite dental restorative materials," Dental Materials, vol. 32, no. 1, pp. 34-42, 2016.

[36] O. Acar, B. Yilmaz, S. H. Altintas, I. Chandrasekaran, and W. M. Johnston, "Color stainability of CAD/CAM and nanocomposite resin materials," The Journal of Prosthetic Dentistry, vol. 115, no. 1, pp. 71-75, 2016.

[37] M. F. Doerner and W. D. Nix, "A method for interpreting the data from depth-sensing indentation instruments," Journal of Materials Research, vol. 1, no. 4, pp. 601-609, 1986.

[38] E. Broitman, "Indentation Hardness Measurements at Macro-, Micro-, and Nanoscale: A Critical Overview," Tribology Letters, vol. 65 , no. $1,2017$.

[39] K. Masouras, R. Akhtar, D. C. Watts, and N. Silikas, "Effect of filler size and shape on local nanoindentation modulus of resincomposites," Journal of Materials Science: Materials in Medicine, vol. 19, no. 12, pp. 3561-3566, 2008.

[40] A. C. Fischer-Cripps, Nanoindentation, Mechanical Engineering LLC, Springer Science+Business Media, 2011.

[41] J. Alcalá, A. E. Giannakopoulos, and S. Suresh, "Continuous measurements of load-penetration curves with spherical microindenters and the estimation of mechanical properties," Journal of Materials Research, vol. 13, no. 5, pp. 1390-1400, 1998.

[42] N. Ilie, T. J. Hilton, S. D. Heintze et al., "Academy of Dental Materials guidance-Resin composites: Part I-Mechanical properties," Dental Materials, vol. 33, no. 8, pp. 880-894, 2017. 


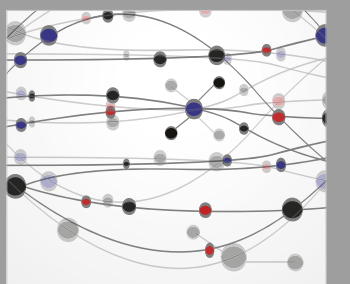

The Scientific World Journal
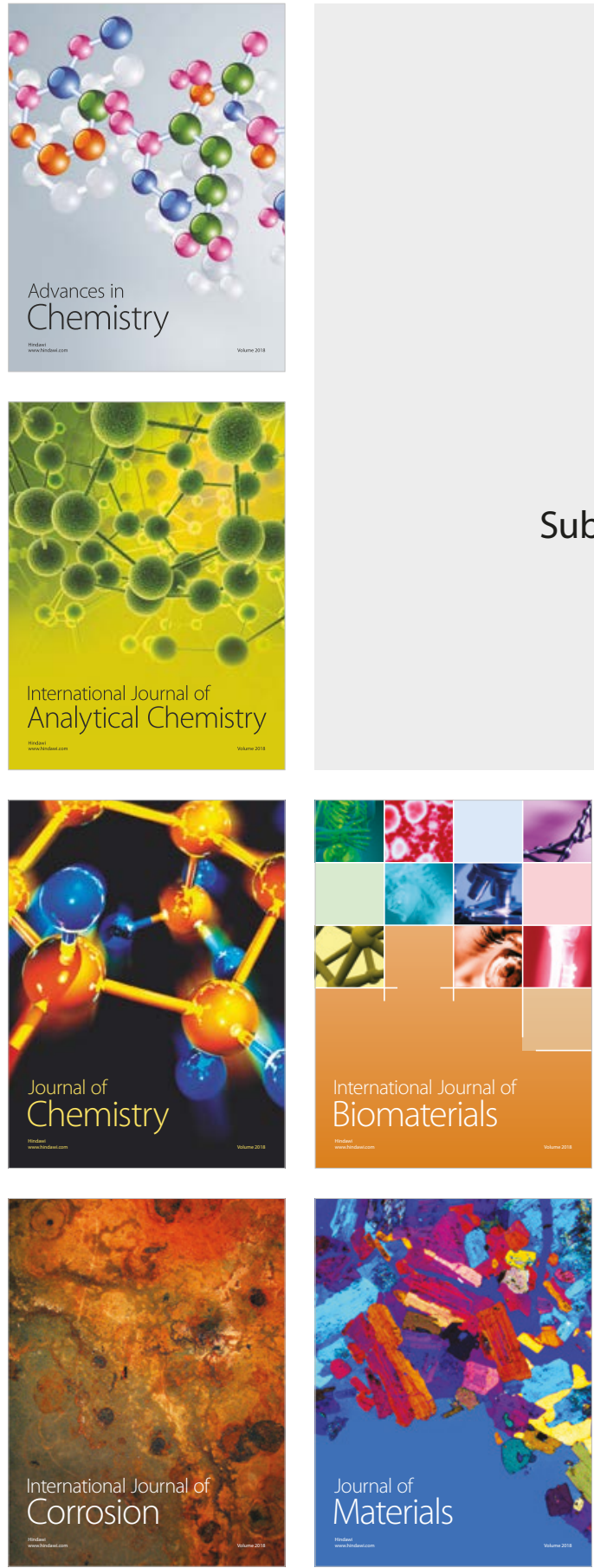

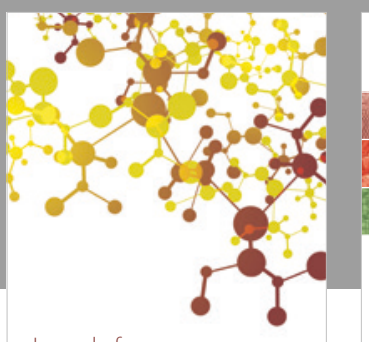

Journal of

Applied Chemistry
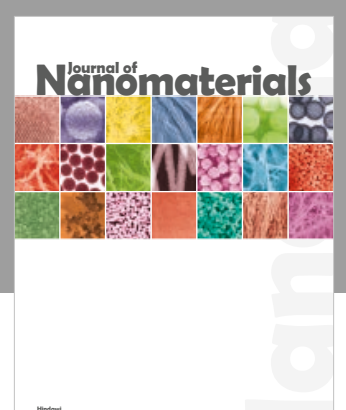

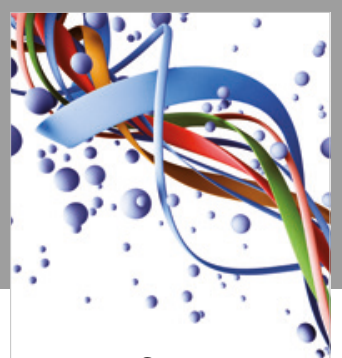

Scientifica

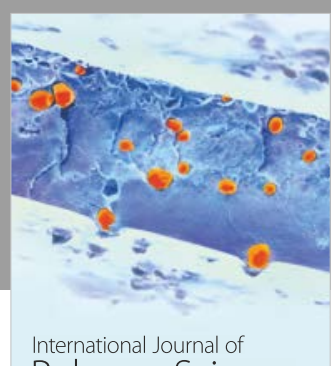

Polymer Science

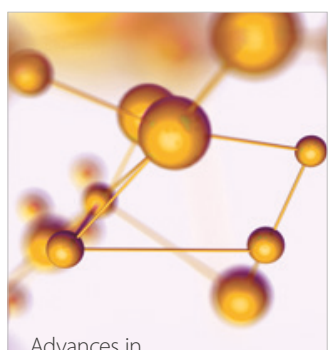

Physical Chemistry
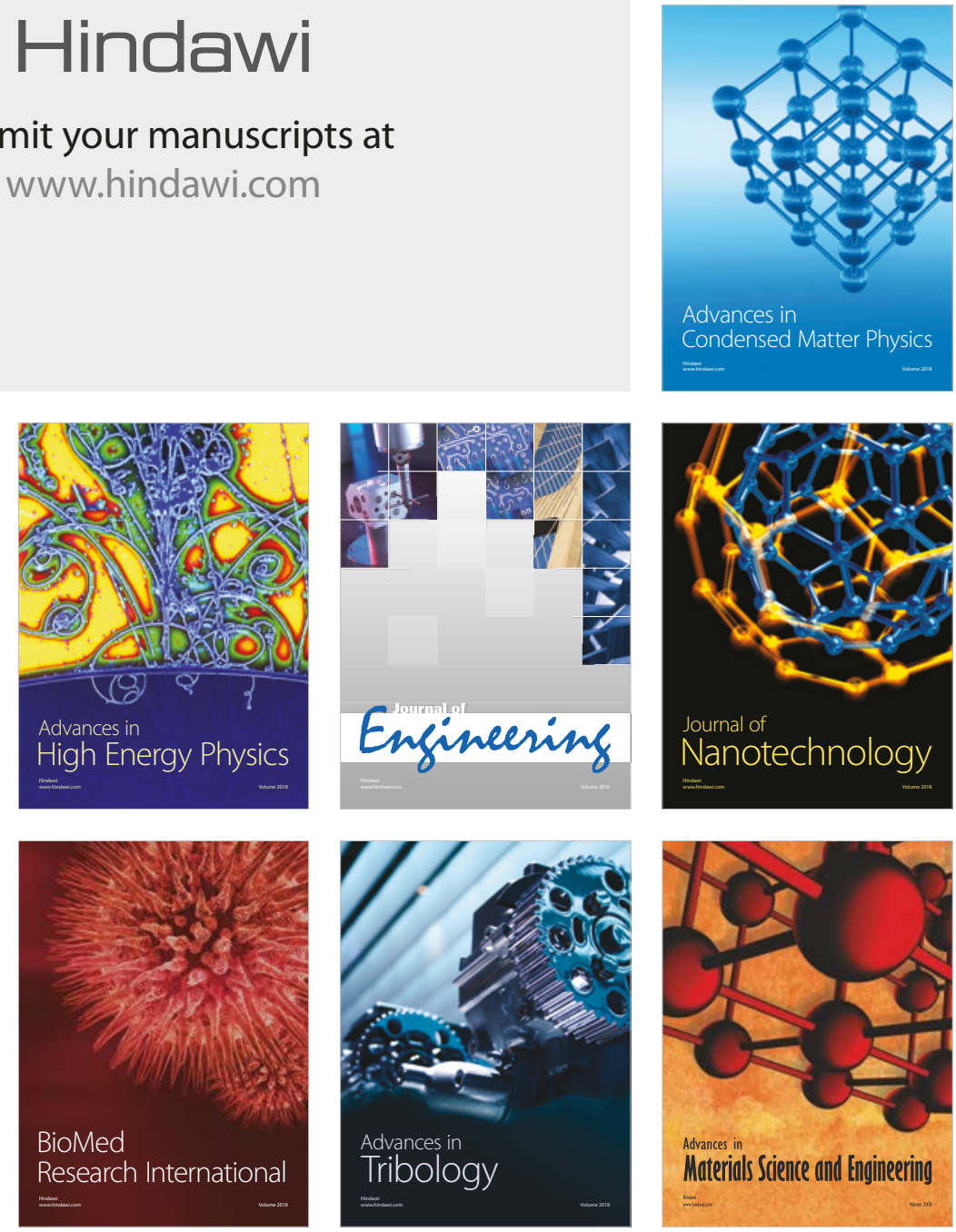